\title{
An explanation for the observed increase in mortality after a birthday in people over 75 years old
}

\author{
J. H. ROGER
}

From the Department of Applied Statistics, Reading University, Berkshire

SUMMARY In a recent analysis, Alderson (1975) presented data that suggested a statistically significant, although numerically small, relationship between the month of birth and the montho of death of elderly people. It is shown here that this relationship was to be expected from the sampling procedure used and was not related to 'birthday stress' factors.

In an elegant study of the months of birth and death of elderly people, Alderson (1975) demonstrated that elderly people were more likely to die during the months succeeding a birthday. To remove any seasonal effect in either the month of birth or month of death, each individual was regarded as dying in a specific month relative to his month of birth, ranging from five months before to six months after. Thus someone born in January who died in November was recorded as -2 , while if he had died in July this would have been +6 . Data collected on a sample of individuals can then be seen as a distribution of deaths over the months before and after the month of birth. Expected values were calculated to take account of any interactive effect between the two seasonal trends.

After certain exclusions, 255164 deaths in 1972 of persons aged 65 years and over were studied by Alderson (1975). Using a method due to Edwards (1961), it was possible to test for any cyclic trend in this distribution for the 12 classes (months before and after birth) denoted by $C(-5)$ up to $C(6)$. A statistically significant cyclic trend was found in deaths of people aged 75 years and over, for all eight distinct subsets of the data defined by sex and marital status. The peak in the distribution in each case was during the months after the birth month. The immediate conclusion was that there might exist some stress factor in having a birthday which increased the chances of mortality in the directly succeeding months. The fact that no such cyclic trend was evident for those who died aged between 65 and 74 years, implied that this stress factor was particularly significant in the very elderly. However, the size of the effect was small: an overall excess of about $1 \%$ of all deaths. It is feasible that some minor systematic error might have led to these observations. There are several possible reasons for a minor systematic error-such $N$ as, the varying number of days in each calendars month. However, with one exception, these reasons were too small to account for the observed periodicity.

\section{Model} The number of deaths in England and Wales In
1972 , extracted from Table 14 of the Regist? General's Statistical Review of England and Wales for 1972 (Office of Population Censuses and Surveys, 1974) for each year over 65 is shown in the Figure. The decrease from year to year is

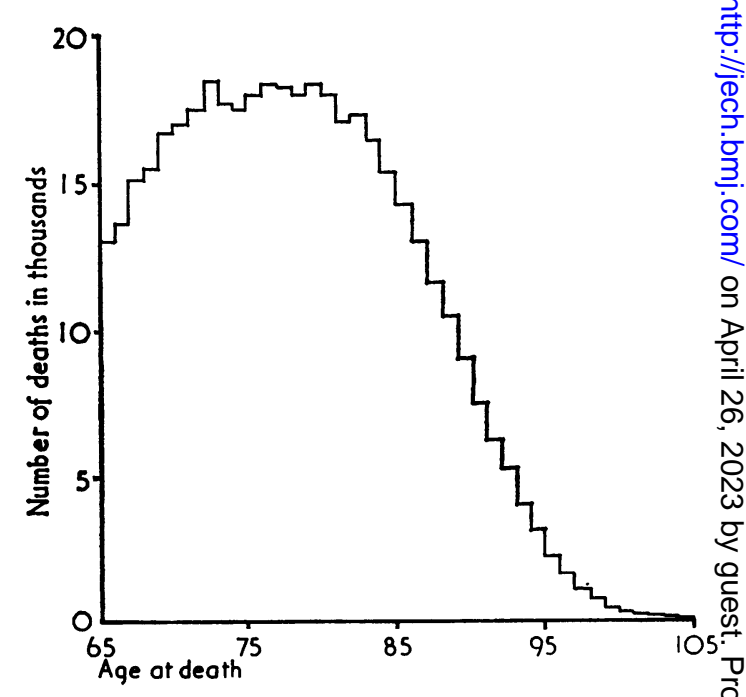

Figure Number of deaths in England and Wales in 19720 by age. 
evident after the age of 80 years. There are two main factors which affect these figures, and they have opposite influences. As the age-specific mortality increases with age the number of deaths will tend to increase. But as the population at risk decreases, due to both earlier mortality and a smaller cohort as defined by year of birth, the actual number of deaths will tend to decrease. Evidently, up to the age of 70 the former effect is pronounced, while after the age of 80 the effect of the dwindling population at risk is more important. Of course, the number dying at specific ages is not only changing from year to year but to a lesser extent from month to month. So if we sum the number dying in each month over successive years, then the total frequencies for the 12 classes will represent an average of these slight changes in the number dying from month to month within each year. Thus in the age range 65 to 74 years (where the number dying increases slightly to age 70 and then remains steady), we may expect the average frequencies to be similar. But over the age of 75 the number dying usually decreases in each successive month. So averaged over the years we can expect the frequency for the 12 classes to vary, with the largest values in the months directly following the starting month. In this case, as the sample includes only those reaching the age of 75 , this initial month is the one following the birth month. However, to be certain that this thesis can explain the observed data, it is necessary to see how large is this effect.

We will define a notation such that $D(i, k)$ is the expected number dying in the class $C(i)$ who are aged $k$. Also $D(-, k)$ is the total expected number dying aged $k$. If there are no annual trends related to birthdays then we would expect that for $i$ taking values -5 up to 6 ,

$$
\begin{aligned}
& \mathrm{D}(\mathrm{i}, \mathrm{k}) \simeq\{(13-2 \mathrm{i}) \times \mathrm{D}(-, \mathrm{k}-1)+(11+2 \mathrm{i}) \times \\
& \mathrm{D}(-, \mathrm{k})\} / 288
\end{aligned}
$$

There are better approximations, but this piecewise linear one will suffice. We fix attention on the period from age $k_{1}$ up to age $k_{2}$ and define $D(i,-)$ as the total expected number of deaths in each month relative to birthday summed over all the ages $k_{1}$ up to and including age $k_{2}$. Summing the approximation for $D(i, k)$ over $k$ we see that, $\mathrm{D}(\mathrm{i},-) \simeq \mathrm{D}(-,-) / 12+\{(13-2 \mathrm{i}) \times$ $\left.\left(\mathrm{D}\left(-, \mathrm{k}_{1}-1\right)-\mathrm{D}\left(-, \mathrm{k}_{2}\right)\right)\right\} / 288$ where $\mathrm{D}(-,-)$ is $\Sigma \mathrm{D}(-, \mathrm{k})$ with summation for $k$ from $k_{1}$ to $k_{2}$.

This means that the expected frequencies will have a trend which could be confused with a cyclic one, as long as the numbers dying each year at the extremes of the period are not equal. This is most extreme for those dying over the age 75 , as in this instance $\mathrm{D}\left(-, \mathrm{k}_{2}\right)$ will be nearly zero.

\section{Results}

If we consider all deaths over the age of 75 in 1972 we find expected proportions:

$\frac{D(i,-)}{D(-,-)}=1 / 12+(13-2 i) \times\left(\frac{18000}{288 \times 267388}\right)$
$=1 / 12+(13-2 i) \times 0.000234$.

This then is equivalent to a maximum deviation in any category of the order of $3 \%$. So this effect is of an equivalent size to the apparent seasonality observed by Alderson (1975).

There is one more complicating factor, the data collected by Alderson (1975) classify the deaths depending upon whether the actual calendar month of birth is the same as the calendar month of death. So of those deaths in the month after a birthday, half will be allocated to class $C(0)$ and half to the class $C(1)$, depending on whether a new calendar month occurs in the interval between the birthday and death. Then the expected number in class $C(1)$ is $\frac{1}{2}(D(1,-)+D(2,-))$, in class $C(2)$ is $\frac{1}{2}(D(2,-)+D(3,-))$, and so on.

Using figures from the Office of Population Censuses and Surveys (1974) for the age-specific mortality in 1972 in each of the sex/marital classes we can calculate corrections to the expected numbers in each of the 12 monthly categories. As an example, the 'observed minus expected' numbers before and after this correction of the expected numbers are shown in Table 1 , for married men.

It is possible to test the fit of the observed frequencies to the expected values using the usual Pearson $\chi^{2}$ with 11 degrees of freedom. Also one can test for seasonality using the extension of Edwards's test due to Walter and Elwood (1975),

Table 1 Difference between observed and expected number of deaths before and after correction for systematic

\begin{tabular}{|c|c|c|c|c|c|c|c|c|c|c|c|c|}
\hline & -5 & -4 & -3 & -2 & -1 & $\begin{array}{l}\text { Birth } \\
\text { month }\end{array}$ & +1 & +2 & +3 & +4 & +5 & +6 \\
\hline Observed-expected & -105 & -38 & -85 & -212 & -170 & 98 & 221 & 235 & 183 & 9 & -119 & -18 \\
\hline $\begin{array}{l}\text { Observed-expected } \\
\text { (after correction for systematic } \\
\text { trend, see text) }\end{array}$ & -65 & 42 & 35 & -52 & +36 & 98 & 21 & 75 & 63 & -71 & -159 & -18 \\
\hline
\end{tabular}
trend in mortality for married men aged 75 years and over for 1972 
Table 2 Levels of significance obtained in tests of goodness of fit with two different sets of expected values

\begin{tabular}{|c|c|c|c|c|}
\hline \multirow{2}{*}{ Subpopulation } & \multicolumn{2}{|c|}{ Expected values (Alderson, 1975) } & \multicolumn{2}{|c|}{ Expected values corrected for systematic trend } \\
\hline & $\begin{array}{l}\text { Pearson } \chi^{2} \\
11 D F\end{array}$ & $\begin{array}{l}\text { Test for cyclic } \\
\text { trend (seasonality) }\end{array}$ & $\begin{array}{l}\text { Pearson } x^{2} \\
11 \mathrm{DF}\end{array}$ & $\begin{array}{l}\text { Test for cyclic } \\
\text { trend (seasonality) }\end{array}$ \\
\hline $\begin{array}{l}\text { Men } \\
\text { Single } \\
\text { Married } \\
\text { Widowed } \\
\text { Other }\end{array}$ & $\begin{array}{l}\text { NS } \\
<0.001 \\
<0.01 \\
\text { NS }\end{array}$ & $\begin{array}{l}<0.05 \\
<0.001 \\
<0.005 \\
<0.01\end{array}$ & $\begin{array}{l}\text { NS } \\
\text { NS } \\
\text { NS } \\
\text { NS }\end{array}$ & $\begin{array}{l}\text { NS } \\
\text { NS } \\
\text { NS } \\
<0.05\end{array}$ \\
\hline $\begin{array}{l}\text { Women } \\
\text { Single } \\
\text { Married } \\
\text { Widowed } \\
\text { Other }\end{array}$ & $\begin{array}{l}\text { NS } \\
<0.001 \\
\text { NS } \\
<0.05\end{array}$ & $\begin{array}{l}<0.05 \\
<0.001 \\
<0.005 \\
<0.001\end{array}$ & $\begin{array}{l}\text { NS } \\
\text { NS } \\
\text { NS } \\
<0.05\end{array}$ & $\begin{array}{l}\text { NS } \\
\text { NS } \\
\text { NS } \\
<0.01\end{array}$ \\
\hline
\end{tabular}

or by using the alternative statistic $\mathrm{R}$ of Roger (1977). The two tests for seasonality are asymptotically equivalent, when the expected values are equal in each category.

In Table 2 the results of the significance tests using the Pearson $\chi^{2}$ and the $R$ test statistic are given for both the original 'expected' values and the revised values. It is clear from this table that using the revised expected values there is little evidence for the cyclic trend in mortality relative to birth date. The only exception is in the two subgroups of those with marital status 'other' (divorced or not stated). The sample sizes in these subgroups are much smaller than for the rest of the data. Although it is not immediately clear why these two subpopulations should show such a cyclic trend, it is evident that, with the absence of any such trend in the rest of the data, there is little evidence for an increased rate of mortality after birthdays in the aged.

I am grateful to Professor Alderson for correspondence on this matter.
Reprints from J. H. Roger, Department of Appliedo Statistics, Reading University, Whiteknights, Read-ه ing, Berkshire RG6 2AN.

\section{References}

Alderson, M. (1975). Relationship between month of birth and month of death in the elderly. British Journal of Preventive and Social Medicine, 29, 151-156

Edwards, J. H. (1961). The recognition and estimation of cyclic trends. Annals of Human Genetics, 25, 83-87. $\vec{\bullet}$

Office of Population Censuses and Surveys (1977) Registrar General's Statistical Review of England and Wales for the Year 1972, Part I: Tables, Medialo HMSO: London.

Roger, J. H. (1977). A significance test for cyclic trends్ in incidence data. Biometrika, 64 (In press).

Walter, S. D., and Elwood, J. M. (1975). A test fo? seasonality of events with a variable population at risk British Journal of Preventive and Social Medicine, 29\% 18-21. 